José Teixeira

Universidade do Minho

jsteixeira@ilch.uminho.pt

\title{
As cores dos provérbios na língua portuguesa: de Portugal ao Brasil e de Angola a Timor
}

\begin{abstract}
Resumo:
Linguisticamente, os provérbios possuem, a nível semântico-pragmático, uma estrutura relativamente autónoma, podendo até serem considerados, numa determinada ótica, uma espécie de microtextos. Esta sua caraterística levou-nos a utilizá-los para testar os mecanismos de sinestesia nas línguas, concretamente, tentar perceber se os provérbios não ligados diretamente a cores (como "Quem tudo quer, tudo perde") desencadeiam processos semântico-cognitivos implicando as cores de forma não aleatória.

Para tal, a partir de um grupo de 9 provérbios sem referências diretas a cores recolheram-se as respostas a um conjunto de inquéritos feitos em Portugal e no Brasil que evidenciam a sistematicidade de, por um lado, se poder dizer que cada provérbio tem cores específicas e por outro que há diferenças entre essas cores para o Português Europeu (PE) e para o Português Brasileiro (PB).

Numa segunda fase, recolhemos dados sobre os mesmos provérbios em Angola (PA, Português de Angola) e Timor (PTi, Português de Timor) com a finalidade de se verificar até que ponto as sinestesias das cores nos provérbios são ou não sistemáticas e as relações entre línguas e culturas que essas diferenças podem evidenciar.
\end{abstract}

Palavras chave: sinestesia e significado linguístico, cores e significado linguístico 


\begin{abstract}
:
The Colors of Proverbs in Portuguese: From Portugal to Brazil and from Angola to Timor

At the semantic-pragmatic level proverbs have a relatively autonomous structure and may even be considered, somehow, a kind of microtexts. This characteristic has led us to use them to test the mechanisms of synesthesia in languages, namely to try to understand whether proverbs not directly linked to color (such as the Portuguese proverb "Who wants everything, loses everything") provoke semantic-cognitive processes that imply non-random color associations.

For this, from a group of 9 Portuguese proverbs without direct reference to color, we collect the answers given to a set of surveys carried out in Portugal (EP - European Portuguese) and in Brazil (BP - Brazilian Portuguese), which, on the one hand, show that we can say that each proverb has specific colors and, on the other hand, that there are differences between these colors for EP and BP.

In a second phase, we collected data on the same proverbs in Angola (AP - Angola Portuguese) and East Timor (TiP - East Timor Portuguese) in order to compare the results with those obtained in Portugal and Brazil and thus try to verify some relations between languages and cultures that these differences may show.
\end{abstract}

Keywords: synesthesia and linguistic meaning, colors and linguistic meaning

\title{
1. As cores e a sinestesia: entre a dimensão psicológica e a retórica
}

O conceito de sinestesia designa tradicionalmente um conjunto de fenómenos em que perceções que por norma estão ligadas a um sentido sejam atribuídas a um outro sentido diferente. As cores ligam-se, por norma, aos objetos percebidos pela visão, enquanto os sons aos captados pela audição. Por isso, quando as impressões de cor são atribuídas a perceções auditivas (por exemplo, uma nota musical percebida como se fosse uma cor) ou uma cor é associada a um som, diz-se estar-se diante de perceções sinestésicas. Como refere Beeli,

Synaesthesia is a fascinating perceptual phenomenon in which certain stimuli elicit a sensation in two or more sensory modalities; for example, specific tones may automatically evoke the perception of particular colors. There are different kinds of linkages between sensory modalities, 
the most frequent being linkages of letters and digits (graphemes) with colors (Beeli [et al.] 2007: 788)

Têm sido maioritariamente investigadas e estudadas estas ligações fora da perceção habitual sobretudo entre as cores, as letras e os números. Nos estudos da Psicologia, as investigações sobre a sinestesia costumam ver este fenómeno como partindo de "cruzamentos cognitivos não normais". Assim, baseando-se nesta perceção, diferenciam-se os cérebros "sinestetas" dos cérebros normais ("neural mechanisms for the processing of words in normal (non-synesthetes') brains." Yokoyama [et al.] 2014: 361).

Na retórica clássica, contudo, há uma longa tradição em que a sinestesia é vista como manifestação estilística da linguagem e inserida nas noções de "figuras de estilo". Implica isto que os exemplos linguísticos de sinestesia sempre foram entendidos como artifícios linguísticos (e ligados à literariedade e "função poética"). Era através deles que a linguagem acentuava figurativamente (daí "figuras de estilo") determinadas formas de expressão. Exemplos como cor pesada/leve, um som pesado/leve/ escuro/luminoso/claro ou sinfonia de cores exemplificam a normalidade na comunicação linguística destes usos sinestésicos.

Nas últimas duas décadas, no entanto, o maior conhecimento sobre a cognição parece demonstrar que as associações sinestésicas, aparentemente inexplicáveis, podem advir de correlações cognitivamente compreensíveis e que justificam a ideia de a sinestesia ter um papel tão histórico no interior da tradição de análise linguística. Assim, a Psicologia parece também aceitar que a sinestesia não será apenas um fenómeno percetivo extralinguístico, mas conectado com fenómenos linguístico-percetivos, sobretudo no domínio do significado:

Although synesthesia has been described as a perceptual phenomenon, recent studies began to focus on linguistic aspects of synesthesia.

One of the most interesting topics is a synesthetic color triggered by words (not letters). [...] Recent studies further reported the third case where lexical colors might be influenced by semantic information of words. (Yokoyama [et al.] 2014: 360) 


\title{
2. Os dados recolhidos
}

Numa primeira fase, tentamos perceber até que ponto, no funcionamento normal da língua portuguesa, se associam cores específicas ao significado. Ou seja: a componente das cores será uma componente relevante para a forma como os nossos cérebros atribuem às frases o significado linguístico?

A resposta evidente será que em palavras como laranja, limão, alface, céu, sangue, tomate a dimensão [cor], dentro do significado da palavra, parece fundamental. Mas quando não há referência direta a cores, como por exemplo nos conceitos mais abstratos?

Para verificar esta hipótese, selecionaram-se 9 provérbios do Português Europeu (PE) e do Português Brasileiro (PB) que fossem muito conhecidos e usados e que não contivessem palavras diretamente ligadas a cores. Nesta primeira fase (em 2017), foram realizados em Portugal 573 inquéritos e no Brasil 270 (Figura 1).

Figura 1: Folha de inquérito em Portugal

Inquérito $\mathrm{N}^{2}$

Idade: [ ]16-25; [ ] 26-40; [ ]41-60; [ ] 61 ou+

\begin{abstract}
Se para cada proverbio tivesse que escolher uma cor, qual a cor mais adequada para cada um dos seguintes? (Pode repetir as cores; nป̄o é preciso serem sempre cores diferentes):
\end{abstract}

1. Quem com ferro mato com ferro morre. Cor adequada:

2. Mois vale torde do que nunca. Coe adequada:

3. Quem tudo quer tudo perde. Cor adequada:

4. Amar com amor se poga. Cor adequada:

5. O fruto proibido te o mais apetecido. Cor adequada:

6. Só a morte é que nôlo tem remédio. Cor adequada:

7. Mois vale um pássaro na mäo do que dois a voor. Cor adequada:

8. Filho de peine sabe nodar. Cor adequada:

9. Águo male em pedra dura tonto bote oté que fura. Cor adequada:

Os inquéritos não foram feitos em laboratório, mas presencialmente e alguns por resposta dada através de inquérito online e recolhidos por alunos da Universidade do Minho. O inquirido, depois de ouvir o provérbio, dizia/escrevia uma cor que lhe parecia dever ser associada ao respetivo significado. Para comparar com estes dados, em 2018 foram realizados em Angola 606 inquéritos e em Timor 114 inquéritos. 
Apesar de serem os mesmos provérbios, há em alguns pequenas variações formais entre o $\mathrm{PE}$ e o $\mathrm{PB}$ nos provérbios 1, 2, 5, 6, 7 e 8 . No provérbio 8 os inquéritos em Angola ( $\mathrm{PA}=$ Português de Angola) utilizaram a variante do Brasil (PB). Em Timor (PTi= Português de Timor), a versão portuguesa foi a usada e considerada a mais conhecida (Figura 2).

Figura 2: Variações formais entre o PE, PB e PTi

\begin{tabular}{|c|c|c|}
\hline $\mathbf{N}^{\mathbf{0}}$ & Provérbios (PE) & Diferenças PB, PAe PTi \\
\hline 1. & $\begin{array}{l}\text { Quem com ferro mata com ferro } \\
\text { morre. }\end{array}$ & $\begin{array}{l}\text { Quem com ferro fere, com ferro será } \\
\text { ferido. }(\mathrm{PB})\end{array}$ \\
\hline 2. & Mais vale tarde do que nunca. & Antes tarde do que nunca. (PB) \\
\hline 3. & Quem tudo quer tudo perde. & \\
\hline 4. & Amor com amor se paga. & \\
\hline 5. & $\begin{array}{l}\text { O fruto proibido é o mais ape- } \\
\text { tecido. }\end{array}$ & O fruto proibido é mais gostoso. (PB) \\
\hline 6. & $\begin{array}{c}\text { Só a morte é que não tem } \\
\text { remédio. }\end{array}$ & $\begin{array}{c}\text { Há remédio para tudo, menos para } \\
\text { a morte. }(\mathrm{PB})\end{array}$ \\
\hline 7. & $\begin{array}{l}\text { Mais vale um pássaro na mão } \\
\text { do que dois a voar. }\end{array}$ & $\begin{array}{l}\text { Mais vale um pássaro na mão do que } \\
\text { dois voando.(PB) }\end{array}$ \\
\hline 8. & Filho de peixe sabe nadar. & Filho de peixe peixinho é. (PB) (PA) \\
\hline 9. & $\begin{array}{c}\text { Água mole em pedra dura tanto } \\
\text { bate até que fura. }\end{array}$ & \\
\hline
\end{tabular}

\section{O significado dos provérbios implica sistematicidade cromática}

A primeira questão a ser colocada teria que ser verificar se a associação cor-significado / provérbio é pessoal, subjetiva (e portanto aleatória) ou se se encontram padrões sistemáticos. Na verdade, se a primeira suposição fosse verdadeira, pouco interesse teriam as associações de cor encontradas para tentarmos perceber o funcionamento do sistema linguístico-cognitivo. Já se a última hipótese se confirmasse, tal poderá indiciar que o significado linguístico implica redes/“clusters" 
em que a cor tem importantes relações metonímicas, metafóricas e sinestésicas.

Desde a recolha e sistematização inicial dos resultados de 2017, em que comparamos dois grupos do $\mathrm{PE}^{1}$ com um grupo de $\mathrm{PB}$, saltava à vista, imediatamente, que não são meras coincidências as semelhanças dos gráficos de cores para cada provérbio. Não apenas em um ou outro caso, mas em todos. E não apenas entre os dois grupos do PE, mas também entre estes e o do PB. As cores mais destacadas em cada grupo de inquiridos, para cada um dos provérbios, são consistentemente dominantes, nos outros grupos, para o mesmo provérbio.

Uma segunda hipótese a verificar seria se cores acionadas e o respetivo peso percentual (ou seja, a "paleta" do provérbio) são mais ou menos as mesmas para todos. Uma comparação entre os resultados dos nove provérbios evidencia, logo a um primeiro olhar, a identidade cromática de cada um² $^{2}$.

E o que é que provoca as associações semântico-cognitivas com as cores acionadas?: o significado lexical de uma dada palavra ou o valor semântico global do provérbio?

Analisando os resultados, pode concluir-se que são as duas vertentes. Por exemplo, para o PE, se no provérbio 8 (Filho de peixe sabe nadar) (Figura 12a) se compreende que o domínio absoluto do azul $(73 \%)$ é provocado por peixe+nadar $>$ mar $>a z u l$ e que isto se liga à referencialidade física e cromática de mar, há, por outro lado, situações em que não há palavras que individualmente se possam, de uma forma direta, associar a cores, tendo o acionamento destas que ter sido provocado pela semântica global da construção. No provérbio 3. Quem tudo quer tudo perde (Figuras 7a, 7b, 7c e 7d) deverão ser associações sinestésicas que justificam os resultados, já que os valores

${ }^{1}$ Para testar a não aleatoriedade dos resultados, dividimos os inquéritos do $\mathrm{PE}$ em dois grupos: um com os primeiros 300 inquéritos recebidos (Grupo 1) e outro com os restantes 273 (Grupo 2).

${ }^{2}$ Para não repetir aqui a apresentação dos gráficos e das análises que mostram a coincidência entre os resultados dos dois grupos do PE entre si e também com o grupo do PB, bem assim como a identidade de cada "paleta" de cada provérbio, ver Teixeira 2018a, Teixeira 2018b, Teixeira 2019 e Teixeira S/D. 
das cores maioritariamente evocadas decorrem de associações não conectáveis com qualquer palavra individual do provérbio. Assim, aqui, o preto e a sua cor complementar, cinzento, são as cores dominantes, já que implicam os valores [perder] e [tristeza], essenciais ao preto e que o cinzento reforça. Por sua vez, o mesmo cinzento é provocado pelos valores de [equivalência]/ [indistinção] que estruturam a semântica global do provérbio: querer tudo é apresentado como equivalente a perder tudo. O vermelho é também uma cor com elevada importância, aqui, porque a semântica global do provérbio evoca [ações de risco], [perigo], [desafios], [jogo], [ganhar], valores que esta cor sinestesicamente aciona. E para os valores/as cores secundariamente implicados para o mesmo provérbio, encontramos [esperança] (amarelo e verde) e a [racionalidade] (azul) da equivalência que o provérbio propõe (querer tudo é arriscar-se a perder tudo) ${ }^{3}$.

\section{Cores dos provérbios no português policêntrico}

Segundo Berlin e Kay (1969: 2-3) há um conjunto de princípios que presidem ao processo de lexicalização das cores numa língua (Figura 3).

Figura 3: representação dos termos básicos de cor (adaptado de Berlin, Kay, 1969: 4)

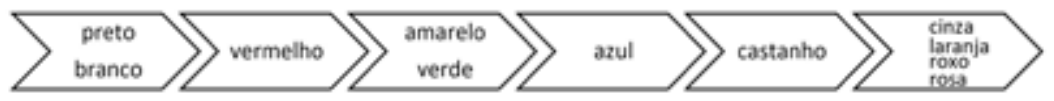

1) Todas as línguas possuem palavras para preto e branco;

2) Se uma língua tiver apenas três palavras para as cores, terá um termo para o vermelho;

3) Se possuir quatro termos, terá palavras para o amarelo ou para o verde (mas não para os dois);

${ }^{3}$ Para ver os outros valores evocados pelas cores dos 9 provérbios do PE, ver Teixeira 2019, "Significado e cores de nove provérbios portugueses sem cor". 
4) Se tiver cinco termos para as cores, terá também para o verde e para o amarelo;

5) Com seis termos, possuirá um para o azul;

6) Se tiver sete nomes de cores, terá um termo para o castanho;

7) Se possuir oito ou mais termos de cor, terá palavras para o roxo, o rosa, o laranja, o cinza e possíveis combinações.

A primeira conclusão sobre os nossos resultados é a de que as cores focais em português são comprovativamente as 11 assinaladas por Berlin.

Figura 4: percentagem do peso total de cada cor nos provérbios inquiridos

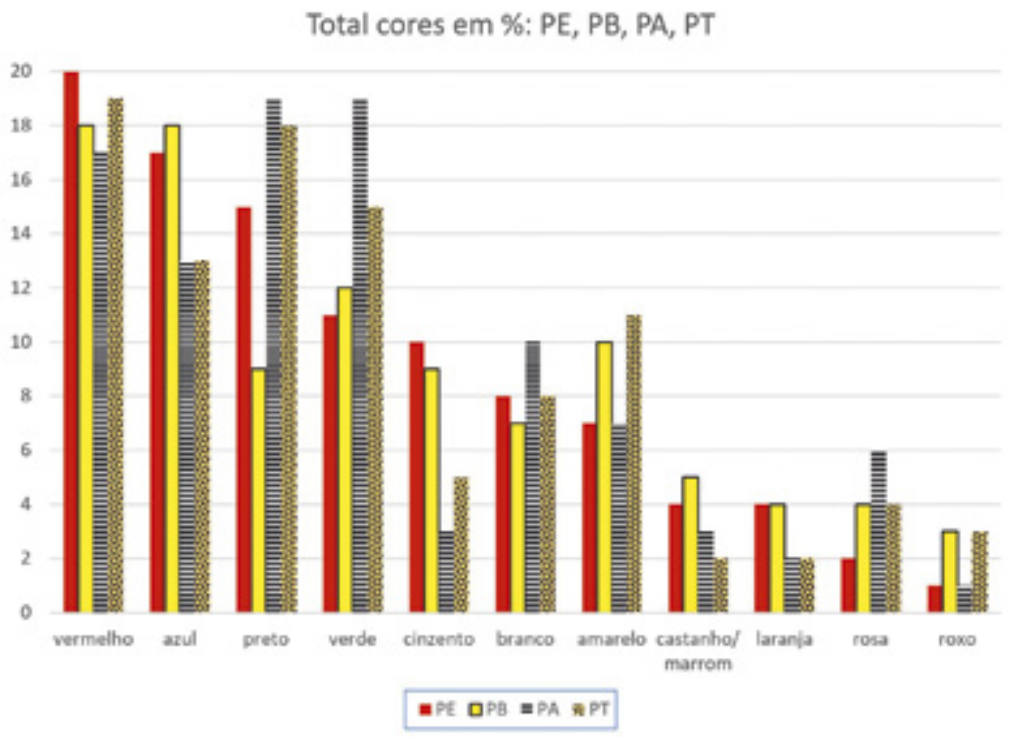

Estas onze cores (Figura 4) são indubitavelmente as cores mais referidas. Todas as outras que apareceram nos inquéritos são residuais, 
de tal forma que a última destas onze em cada variante do português é globalmente referida 10 vezes mais que a seguinte. ${ }^{4}$

Como já se informou, na origem desta série de inquéritos sobre os provérbios e as cores estava a hipótese de verificar se existia alguma regularidade entre os falantes na coloração de provérbios não diretamente referentes a cor (originalmente o corpus era apenas o PE). Depois de verificada a validade desta hipótese, tentamos, então, confirmar se tal regularidade se estendia a demais variantes normativas do português. Ora os dados obtidos confirmam a referida regularidade no sentido de que, globalmente, as cores dominantes em cada provérbio o são quer no PE (Português Europeu), no PB (Português do Brasil), no PA (Português de Angola) ou no PTi (Português de Timor). No entanto, ressaltam algumas diferenças que podem constatar-se e que o gráfico da Figura 4, desde logo, evidencia: o PB parece dar alguma vantagem às cores claras e da natureza (azul, verde, amarelo - curiosamente, as cores da bandeira nacional brasileira) e menos ao preto, enquanto no PA e no PTi o preto tem, juntamente com o vermelho, um peso muito acentuado (curiosamente também, duas cores nucleares nas bandeiras nacionais de Angola e Timor). Variáveis desde a estrutura morfológica do provérbio (matar, PE-ferir, PB) e variáveis culturais podem explicar as diferenças, como a seguir referiremos nas análises comparativas entre os gráficos do PE, PB, PA e PTi.

Para o primeiro provérbio (Quem com ferro mata, com ferro morre, em PB Quem com ferro fere, com ferro será ferido) obtiveram-se os resultados que as Figuras 5a, 5b, 5c e 5d ilustram.

${ }^{4}$ O termo "roxo" está a sofrer concorrência do termo "lilás" que aparece significativamente referido. Excetuando no PTi (Português de Timor) onde não aparece (26 para o roxo, 0 lilás), para o $\mathrm{PE}$ temos 75 roxo e 15 lilás, para o PB 62 roxo e 12 lilás e para o PA 39 roxo e 20 lilás, parecendo ser, portanto, na variante angolana que a variação está mais equilibrada. 
Figuras 5a (1PE); 5b (1PB); 5c (1PA) e 5d (1PTi)
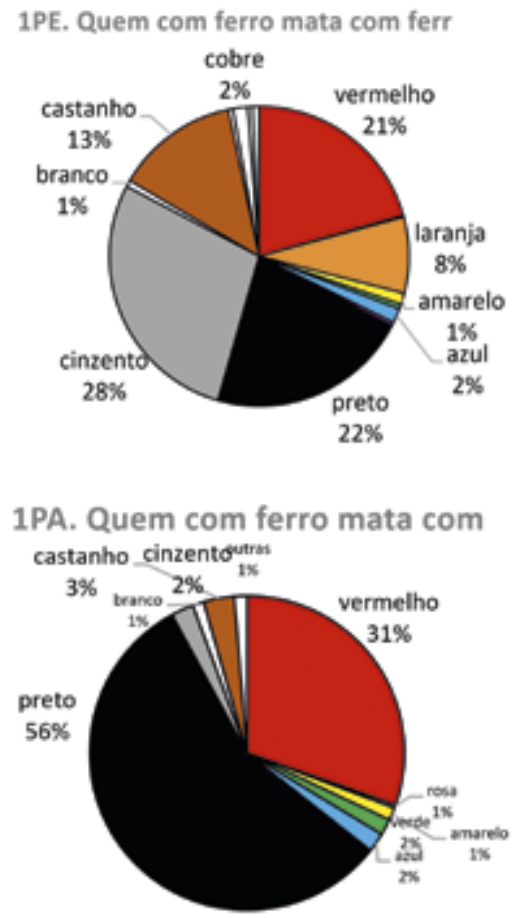
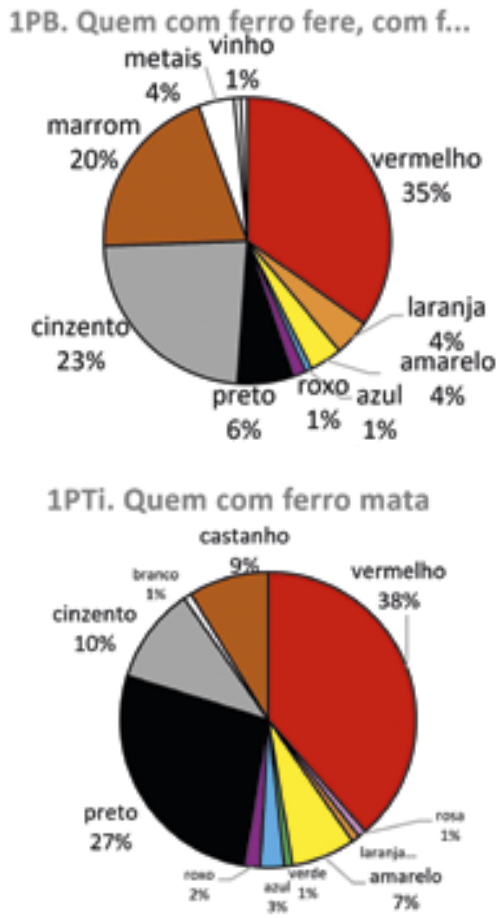

Nota-se que no PB, no PA e no PTi há uma percentagem maior de vermelho comparativamente com o PE. Sendo o frame central do provérbio a morte, talvez para o PA e PTI as memórias recentes das guerras civis expliquem esta dominância. ${ }^{5}$

Já para o Brasil, não se podem invocar as vivências ou memórias de uma guerra civil. No entanto, a formulação brasileira possui

${ }^{5}$ Em Teixeira 2019 ("Significado e cores de nove provérbios portugueses sem cor") apresenta-se, para cada cor acionada por estes 9 provérbios, uma rede cognitiva que explica os principais valores das cores que os inquéritos refletem. Assim, o vermelho estrutura-se numa rede com valores como [sangue, luta, guerra, morte, ações perigosas, ações condenáveis], mas também com valores como [sangue, calor, temperatura, emoção, amor, sexo, etc.]). 
uma variação morfossintática: em vez de "mata/morre" a expressão é "fere/será ferido", o que evoca mais imediatamente [sangue] e por conseguinte o vermelho. Para além disso, embora o Brasil não tenha memória de guerra civil no sentido tradicional, as mortes por crimes de sangue são frequentíssimas e é uma pesada razão para os brasileiros associarem morte não tanto a preto, mas bastante a vermelho (opinião expressa por uma brasileira que participou na recolha dos inquéritos).

Embora para Timor o número de inquéritos seja reduzido e por isso a fundamentação para conclusões menos sólida, é interessante aqui referir a percentagem do roxo $(2 \%)$ muito maior que a existente em PE, PB ou PA. Segunda explica uma pessoa de Timor, "em Timor [...] cor roxa usa-se para enfeitar a casa onde está o defunto (especialmente os adultos) e usa-se também para cobrir a caixão" (relato de timorense em trabalho académico em 2017-2018). Nos inquéritos respondidos por timorenses, as vivências sócio-religiosas parecem ter grande impacto nas perceções linguisticamente expressas pelas cores.

Note-se também como nos inquiridos angolanos o cinza (que ocupa nos outros 3 gráficos do provérbio uma área muito significativa) foi praticamente absorvido pelo preto, enquanto nos inquiridos brasileiros é o inverso: o preto é relativamente diminuto e o cinzento, a seguir ao vermelho, a cor mais referida. Estas opções seguem a tendência geral de a paleta brasileira global preferir as cores claras e o preto ser a cor dominante (curiosamente, tanto como o verde) em Angola. 
Figuras 6a (2PE); 6b (2PB); 6c (2PA) e 6d (2PTi)
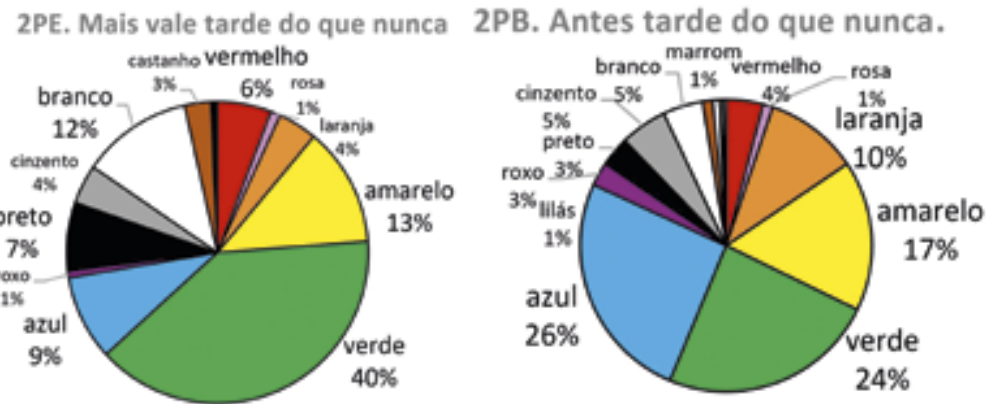

\section{PA. mais vale tarde do}

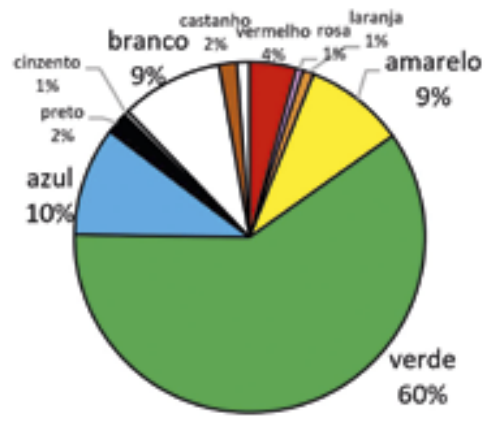

2PTi. mais vale tarde

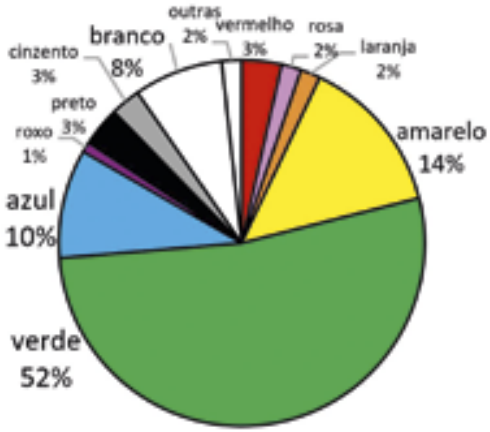

No provérbio 2 (Mais vale tarde do que nunca/ Antes tarde do que nunca, em PB) o grupo verde-amarelo-azul ocupa sensivelmente três quartos dos gráficos. No entanto, o peso de cada uma das cores não é idêntico. No PA e no PTi o verde é predominante, ocupando mais de metade do gráfico. Sendo interessante verificar que estas três cores são as cores da vida e da natureza, o verde aparece aqui como conectado com o valor [esperança], temática central do provérbio. Ora esta associação verde>esperança não é universal, nem tão forte noutras línguas como costuma aparecer no português. Em várias línguas ocidentais (e também no japonês) costuma ser mais associado à inveja.

Esta presença esmagadora do verde (curiosamente muito mais no PA e no PTi) parece justificar que as línguas, através das palavras, 
fazem associações simbólicas a nível sinestésico cor-sentimento que se impõem mesmo em culturas diferentes, como neste caso, entre uma cultura europeia, uma da América do Sul, uma africana e outra asiática. Note-se que este valor [esperança] é aqui acionado pelo sentido global e não por qualquer palavra que apareça no provérbio.

Figuras 7a (3PE); 7b (3PB); 7c (3PA) e 7d (3PTi)

3PE. Quem tudo quer tudo perde

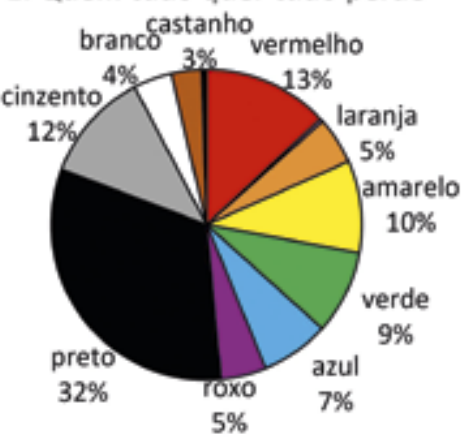

3PA. Quem tudo quer

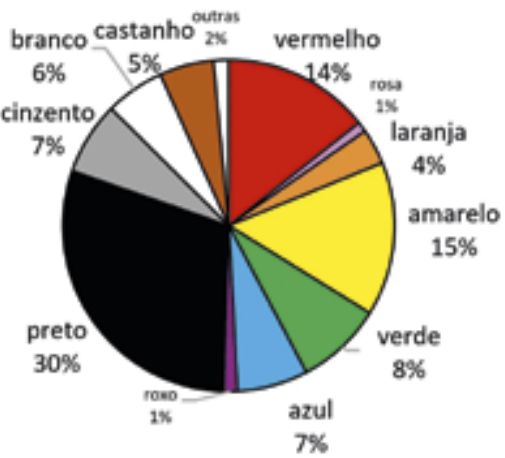

3 PB. Quem tudo quer tudo perde

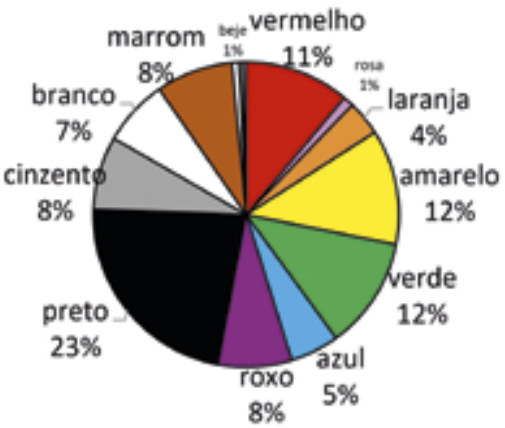

3PTi. Quem tudo quer castanho

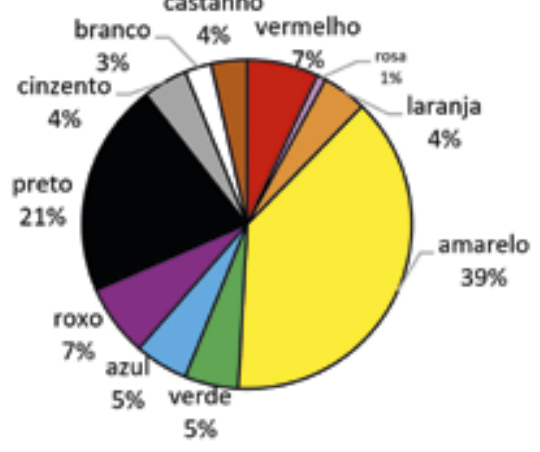

Assentando o provérbio 3 (Quem tudo quer, tudo perde) nos valores de [perigo] e [perder], não admira que preto-cinza e vermelho sejam duas zonas importantes e que tenham relativa equivalência nos quatro 
gráficos. No entanto, no gráfico do PTi a zona amarela é predominante relativamente às outras cores.

A propósito desta constatação, há alguns aspetos a considerar.

Antes de mais, referir o não muito elevado número de inquéritos do PTi, o que significa que pequenas idiossincrasias podem acarretar variações significativas. ${ }^{6}$

Depois, o amarelo e verde parecem fazer um grupo que funciona por osmose ou sistema de vasos comunicantes: o predomínio de uma cor implica a diminuição de outra. Talvez não seja por acaso que em Berlin \& Kay (1969: 4) se diz que se uma língua tiver apenas 4 palavras para cor, a mesma palavra cobre amarelo e verde, o que mostra que os valores sinestésicos de uma cor podem facilmente ser representados pela outra.

Há que aceitar, também, que os valores associativos das cores podem resultar de fatores particulares, quer ao nível cultural, quer ao nível conjuntural. Como já se referiu, são entendíveis os valores de preto-cinza ([perder]) e de vermelho ([perigo de perder tudo]). Mas porquê a alta percentagem de amarelo?

Surpreendentemente, para a I. (19 anos), para este provérbio, a cor que imediatamente referiu foi amarelo. E a explicação que deu foi: PERDER TUDO implica NÃO TER que implica FALTA DE/FALTAR. Então contou que na época em que andava no colégio, entre os adolescentes vestir de amarelo significava "falta de sexo"!

Podemos questionar-nos se será mesmo acaso conjuntural que amarelo apareça associado a "falta de". Se nos lembrarmos que em várias línguas (entre as quais a portuguesa) a cor amarela se associa a [doença/ falta de saúde/ falta de forças] não será que se compreende a sinestesia percetiva?

${ }^{6}$ Idealmente, o número de inquéritos deveria ser o mesmo ou semelhante entre as variedades do Português dos inquiridos. No entanto, tirando o caso do PTi em que o número é bastante inferior, os números das respostas permitem inferir tendências e equivalências globais, que é o que aqui pretendemos, já que não defendemos que é possível indicar a percentagem matemática de cada cor que os falantes hipoteticamente atribuem a um provérbio. 
Figuras 8a (4PE); 8b (4PB); 8c (4PA) e 8d (4PTi)
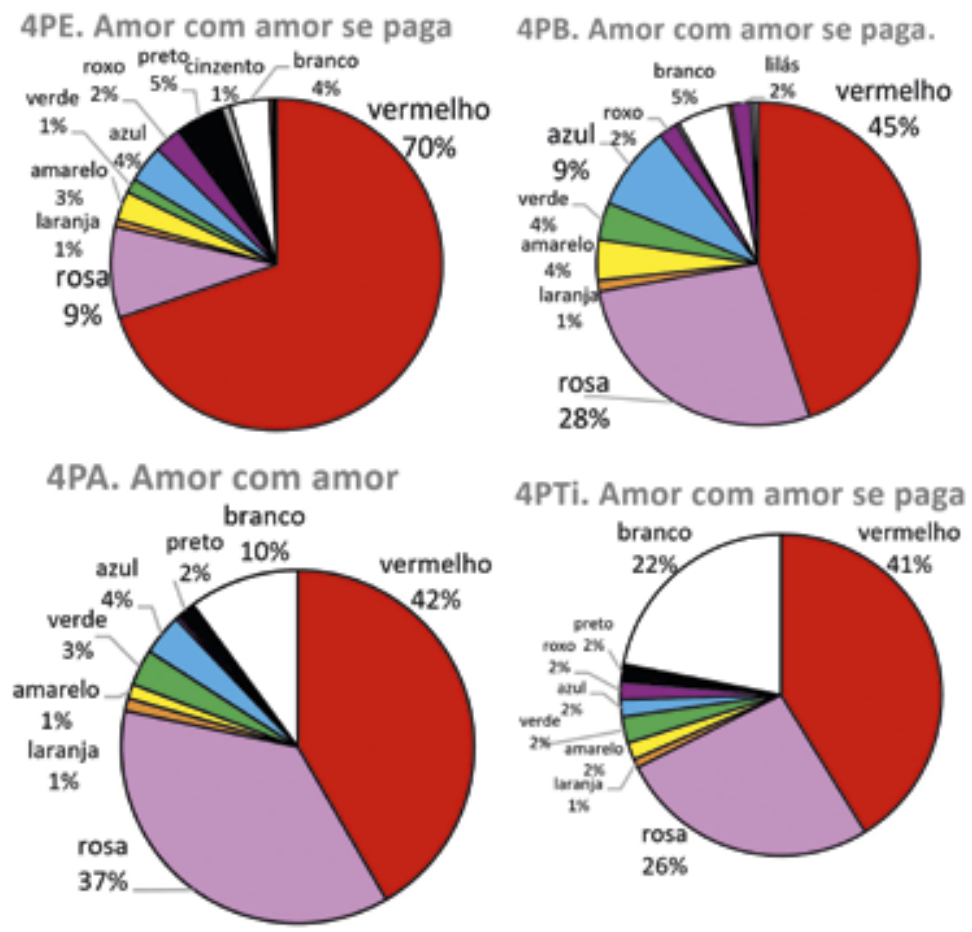

O provérbio 4 (Figuras $8 \mathrm{a}, 8 \mathrm{~b}, 8 \mathrm{c}$ e $8 \mathrm{~d}$-Amor com amor se paga) é um dos que mais facilmente deixa transparecer as associações justificativas das cores. $\mathrm{O}$ vermelho e o cor-de-rosa, conjuntamente, abarcam aproximadamente três quartos de cada gráfico. ${ }^{7}$

7 Não se pense, por exemplo, que a razão do vermelho é apenas a de [amor>sentimento romântico]; o provérbio aciona também o valor [sentimento de vingança] que embora seja muito diferente pode igualmente ser associada ao vermelho. Para a explicação mais completa dos valores acionados pelos provérbios, ver Teixeira (2019: 282-283). 
A cor rosa, muito mais em PB, PA, PTi do que no PE, será explicável por uma dimensão menos sexualizada do amor fora da Europa? ${ }^{8}$ Será que o facto de a resposta poder ter sido dada por mais pessoas do género masculino ou feminino contribuiu para a diferença?

Interessante é notar a presença sempre significativa do branco e o seu enorme peso no PTi. A este propósito é ilustrativo o testemunho de uma pessoa de Timor que em trabalho académico em 2018 escreveu: "em Timor [...] A cor branca, expressa um sentimento de espiritualidade e paz, tal como as pessoas que se casaram virgens, as noivas vestem sempre a roupa de cor branca."

Mais uma vez, tal como já foi referido, parece dever aceitar-se a muito forte dimensão sócio-religiosa em Timor para a associação cores-valores sinestésico-linguísticos.

Para o provérbio 5 (Figuras 9a, 9b, 9c e 9d-O fruto proibido é o mais apetecido; gostoso no $\mathrm{PB}$ ) a dimensão [proibido] (acionando o vermelho e o preto) e a de fruto (ligando-se ao vermelho e ao verde-amarelo) são comuns aos quatro gráficos.

É interessante notar, contudo, que aumentando o preto, diminui o vermelho, o que é particularmente evidente no PB e no PTi. Será lícito inferir que vivências mais restritivas, em sociedades mais proibitivas e carentes não esquecem a ligação proibição-carência, portanto o preto, enquanto sociedades mais libertárias, mais abertas, assentam sobretudo na visão [proibido $>$ desafio $>$ desejo], acionando praticamente só o vermelho?

${ }^{8}$ Os estereótipos que construímos sobre os outros povos costumam levar-nos a pensar numa dimensão mais sexualizada da perceção do amor em culturas como as do PB e PA. Não querendo aqui discutir a fundamentação real ou não deste estereótipo, permita-se que refira apenas que já angolanos e brasileiros me confidenciaram que a forma como se namora em público em Portugal é mais sexualmente desinibida e explícita do que nos respetivos países. A ser verdade, demonstra uma perceção social sobre a relação amor-sexo um pouco diferente de ideias que podemos ter estereotipadas. 
Figuras 9a (5PE); 9b (5PB); 9c (5PA) e 9d (5PTi)
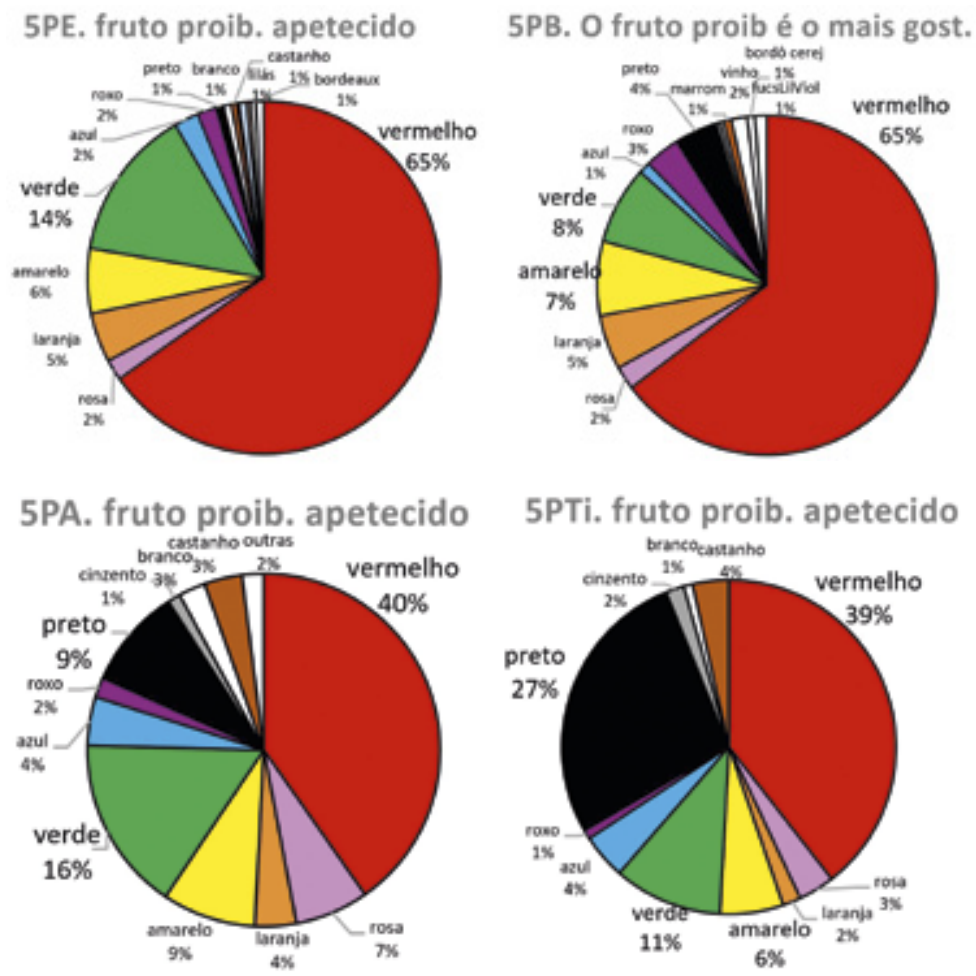

No provérbio 6 (Figuras 10a, 10b, 10c e 10d - Só a morte é que não tem remédio; Há remédio para tudo, menos para a morte, no $\mathrm{PB}$ ) é fácil perceber o porquê de ser o preto-cinzento a coloração dominante, confirmando-se a associação [morte>preto, cinza] e também a associação [morte $>$ branco].${ }^{9}$ A primeira, ocupa mais de metade do

${ }^{9}$ Não sendo, apesar de tudo, a principal finalidade deste texto a procura da associação cores-valores semântico-cognitivos, refira-se que a morte aparece associado ao branco em muitas culturas e religiões, já que é associada a "nova 
espetro de cada gráfico, exceto o do PB que, mais uma vez, inclui menos que os outros o preto-cinza.

Figuras 10a (6PE); 10b (6PB); 10c (6PA) e 10d (6PTi)
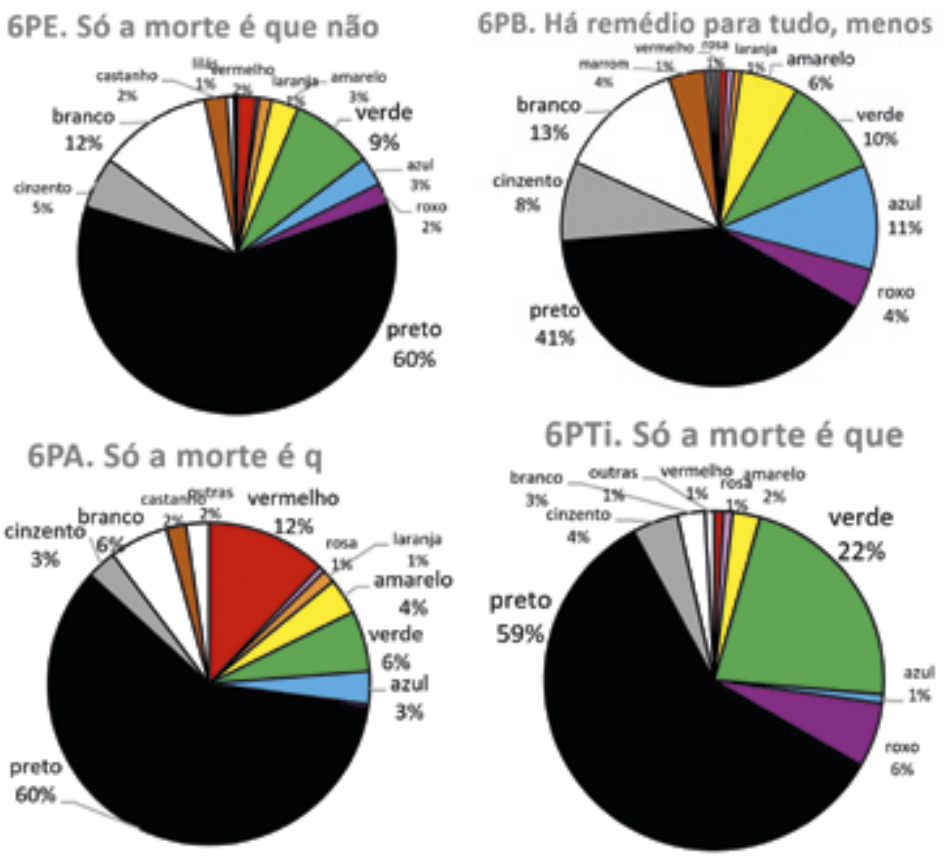

Não será também por acaso que no PTi o roxo detém um valor não negligenciável, $6 \%$, facto único entre todos os provérbios. Recorde-se o que já atrás referimos sobre o relato de uma pessoa de Timor em que explicava que neste país a cor roxa é muito usada em cerimónias fúnebres para enfeitar a casa onde está o defunto e também para cobrir o caixão, reforçando esta referência a ideia do peso que na sociedade timorense têm as vivências sócio-religiosas para as associações cor-significado linguístico.

vida","nova luz", "vida espiritual", "vida eterna" ou "reencarnação". Ver Teixeira (2019: 285-286). 
No PA, o vermelho é muito significativo (a segunda cor mais evocada) enquanto nos outros três gráficos é apenas residual. Terá a ver com as memórias recentes das guerras (da independência e depois guerra civil) em que a morte se associa a morte violenta $>$ sangue $>$ vermelho?

Figuras 11a (7PE); 11b (7PB); 11c (7PA) e 11d (7PTi)
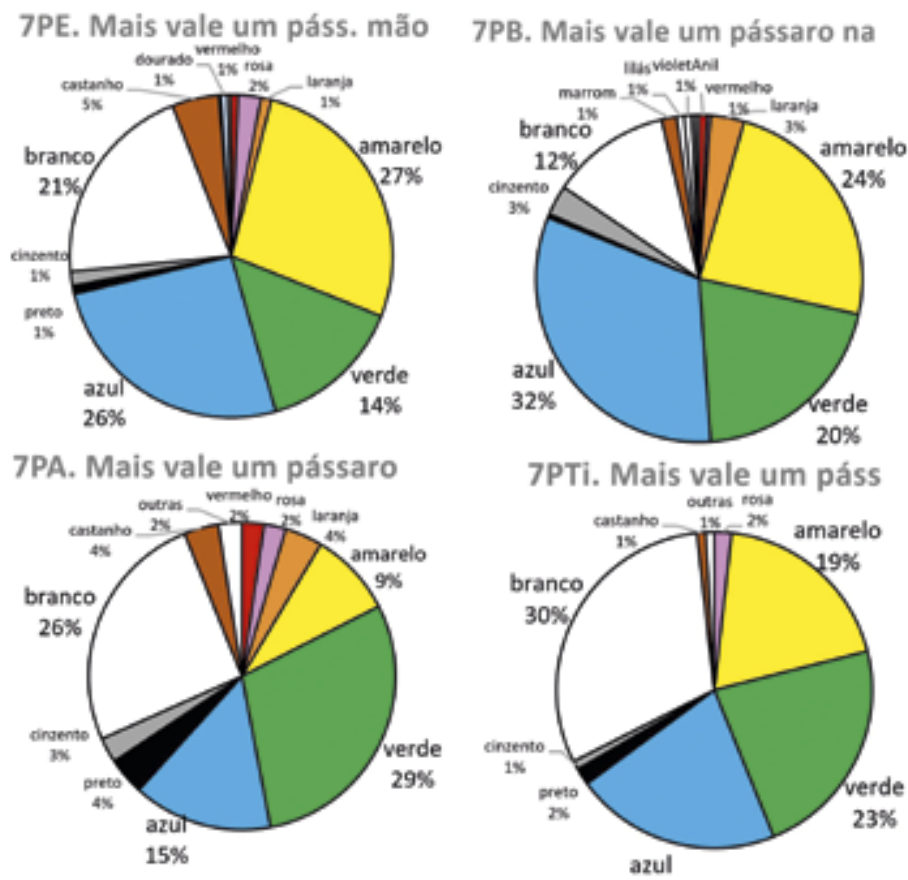

Relativamente ao provérbio 7 (Figuras 11a, 11b, 11c e 11d - Mais vale um pássaro na mão do que dois a voar/voando, no $\mathrm{PB}$ ) descobrem-se quatro paletas muito equivalentes, o que mais uma vez comprova que, antes de tudo, as (des)codificações semânticas envolvem clusters em que a cor não é um elemento aleatório e ainda que o significado linguístico se alicerça em perceções equivalentes, mesmo entre culturas diferentes. Verde-amarelo, azul e branco compõem a quase 
totalidade dos gráficos, facilmente explicável por serem as cores associadas à natureza e ao ar livre, referentes que o significado convoca.

É bastante interessante a amplitude e constância do branco, que parece confirmar que as 4 áreas culturais também associam pássaro a [ar, leveza, luz]. Parece igualmente que, para além das associações à natureza, há duas áreas de cor que balançam entre a esperança (verde-amarelo), e a racionalidade da certeza, de preferir o que é certo (o azul $)^{10}$. É esta, aliás, a semântica global do provérbio, a opção entre a certeza e a esperança. $O$ grande peso do verde e do azul parecem espelhar isso mesmo. Afinal, pode dizer-se que a esperança é a certeza antes de acontecer.

No provérbio 8 (Figuras 12a, 12b, 12c e 12d - Filho de peixe sabe nadar/ Filho de peixe peixinho é, no PB e no PA) é transparente a associação entre o azul (e o branco, talvez também), e a água/mar, o que demonstra que há associações cor-significado comuns às culturas diferentes que subjazem às 4 variantes do português aqui em análise.

Relativamente à relação entre estes resultados e as diferentes vivências culturais, talvez seja interessante reparar na percentagem inesperadamente alta do cor de laranja no PE (6\%) e no PB (8\%). A explicação foi dada por alguns dos inquiridos (pelo menos em PE) que diziam "cor de laranja por causa do peixe Nemo", famosa personagem do cinema de animação à volta da qual há uma série de objetos que muitos jovens têm ou tiveram (mochilas, cadernos, brinquedos). É curioso verificar que esta percentagem relativamente elevada do laranja não se verifica no PA e no PTi, sociedades menos tecnológicas onde a personagem Nemo (e todos os artefactos a ela ligados) deve ser menos conhecida.

${ }^{10}$ As associações de cores poderão ser apenas vistas como acionadas pelos elementos da natureza: o azul será "simplesmente" a associação a céu e o verde/ amarelo às cores dos pássaros. Não negamos que deve ser esta a fundamentação primeira, mas outros valores relacionais-sinestésicos destas cores (esperança, racionalidade) contribuem para o peso que cada cor tem no provérbio. É esse o nosso ponto: há uma margem de importância das cores que é acionada não apenas pelas associações referenciais, mas por associações metonímico-sinestésicas, como em quase todos os provérbios se pode confirmar. 
Figuras 12a (8PE); 12b (8PB); 12c (8PA) e 12d (8PTi)
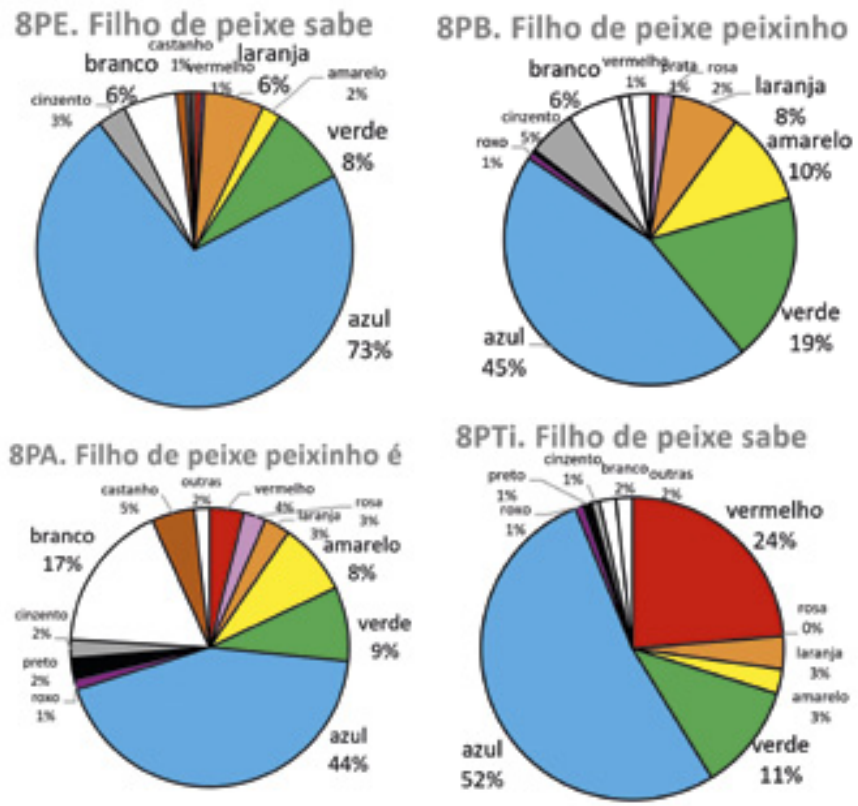

Por fim, um dado de que não temos explicação: Porquê, no PTi, uma tão alta percentagem de vermelho? Diverge de todos os resultados de todos os grupos. Será uma idiossincrasia particular de alguns inquiridos? Terão os peixes em Timor Leste, com frequência, a cor vermelha? Seria interessante verificar se, num universo maior de inquiridos (aqui foram apenas 114), esta percentagem se mantém.

No provérbio 9 (Figuras 13a, 13b, 13c e 13d - Água mole em pedra dura tanto bate até que fura) embora globalmente seja o mesmo o grupo de cores dominantes (cinza, azul, branco, verde, vermelho e preto), cada uma delas obtém valores bastante diferenciados nos quatro gráficos. Isto não implica que o provérbio seja interpretado com significados diferentes ou que as associações significado-cor sejam divergentes, mas o enfoque em cores diferentes pode revelar valores focais diferentes na semântica global do provérbio: Água (azul) 
branco) mole em pedra (cinzento) dura tanto bate (vermelho) até que fura (significado global do provérbio: persistência, esperança, natureza> verde).

Figuras 13a (9PE); 13b (9PB); 13c (9PA) e 13d (9PTi)

\section{PE. Água mole em pedra}

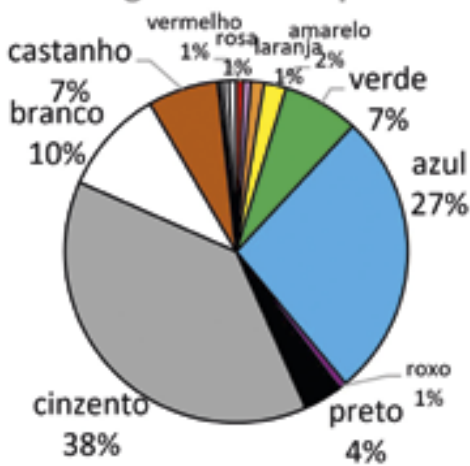

9PA. Água mole em pedra

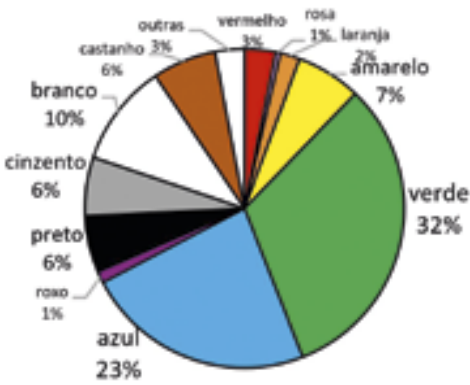

9PB. Água mole em pedra dura
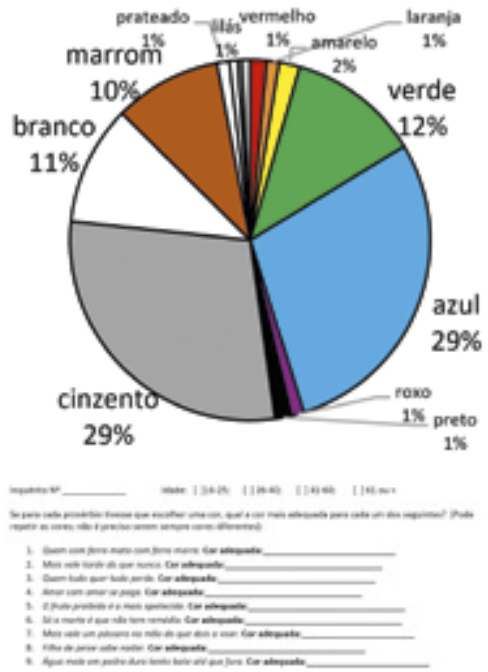

Não se pode deixar de reparar, no entanto, que no PTi o vermelho e o preto são bastante superiores aos dos outros gráficos.

\section{Algumas conclusões}

Este texto, como já atrás foi referido, é uma parte de um conjunto de textos que procuram analisar as associações feitas pelos falantes entre 
as cores e 9 provérbios da língua portuguesa em quatro variantes (PE, PB, PA e PTi). Enquanto noutros se procurou evidenciar a sistematicidade dos resultados e apresentar as razões que levam a pensar que as associações cores-significado linguístico implicam um complexo processo que envolve metonímia, metáfora e sinestesia ("síntonímia"), aqui procuramos contrastar os resultados obtidos nas 4 variantes indicadas.

Neste âmbito, como primeira conclusão, pode constatar-se que cada provérbio apresenta uma paleta global muito equivalente para as 4 variantes referidas. Tal constatação parece comprovar que não decorrerão de meras coincidências os resultados obtidos inicialmente no PE e que, realmente, parece poder detetar-se uma ligação cognitiva entre as cores e o significado linguístico, mesmo entre termos e significados frásicos que não têm elementos coloridos como referentes diretos.

Por outro lado, a comparação entre os resultados nestas 4 variantes indicia que o significado linguístico se alicerça em perceções que se equivalem, mesmo entre culturas diferentes, ou seja, que as bases cognitivas do significado atravessam culturas diferenciadas. Ajuda isto a demonstrar a complexidade da relação entre língua e cultura. Por um lado, se uma mesma língua pode ser língua de culturas variadas, como o português, neste caso, as estruturações semântico-cognitivas da língua também podem transportar para culturas diferentes conexões idiossincráticas da própria língua (por estes resultados, por exemplo a associação esperança-verde, em português).

Assim, parece lícito poder concluir-se que o significado das palavras e das frases é um cluster organizado em rede, mantendo as cores, dentro dessa rede, relações motivadas com a dimensão semântico-cognitiva.

Essas relações motivadas passam pela combinação de fenómenos linguístico-cognitivos como a metonímia, a metáfora ${ }^{11}$ e a sinestesia enquanto instrumentos de organização dos clusters semânticos que

${ }^{11}$ O conceito de metaftonímia (Barcelona 2000; Goossens 1990) apresenta precisamente a ligação entre os fenómenos da metáfora e metonímia a nível concetual. 
a língua organiza, combinação essa que terá que ser vista como essencialmente gradativa em continuum e não como tradicionalmente é apresentada, como se metonímia, metáfora e sinestesia fossem sempre fenómenos discretos. Ou seja, metáfora, metonímia e sinestesia compõem, frequentemente, um todo (que designamos por "sintonímia") no processamento linguístico-cognitivo, sobretudo quando as cores assumem valorações no significado das palavras e das frases. ${ }^{12}$

\section{Referências bibliográficas}

BARCELONA, A. (ed.) (2000), Metaphor and Metonymy at the Crossroads: A Cognitive Perspective, Berlin, Mouton de Gruyter.

BEELI, G., ESSLEN, M., and JÄNCKE, L. (2007), «Frequency Correlates in Grapheme-Color Synaesthesia», Association for Psychological Science, 18(9), pp. 788-792.

BERLIN, B., KAY, P. (1969). Basic Color Terms: Their Universality and Evolution, University of California Press, Berkeley, CA.

GOOSSENS, L. (1990), "Metaphtonymy. The Interaction of Metaphor and Metonymy in Expressions for Linguistic Action", Cognitive Linguistics, 1-3, pp. 323-340, https://doi.org/10.1515/9783110219197.3.349.

YOKOYAMA, T., NOGUCHI, Y., KOGA, H., TACHIBANA, R., SAIKI, J., KAKIGI, R., KITA, S. (2014), "Multiple Neural Mechanisms for Coloring Words in Synesthesia”, NeuroImage, 94, pp. 360-371, https://doi. org/10.1016/j.neuroimage.2014.01.039.

TEIXEIRA, J. (2018a), “As cores dos provérbios: significado linguístico e sinestesia” em: Proceedings/Actas ICP17, 11\%11th Interdisciplinary Colloquium on Proverbs. Colóquio Interdisciplinar sobre Provérbios, Associação Internacional de Paremiologia / International Association of Paremiology (AIP-IAP), Tavira, pp. 380-391.

TEIXEIRA, J. (2018b), “As cores no processamento do significado: provérbios e sinestesia”, Revista Galega de Filoloxía, 19, pp. 131-149, https:// doi.org/10.17979/rgf.2018.19.0.4950.

${ }^{12}$ Como já indicámos, o conceito de "sintonímia" é abordado em textos complementares a este, sobretudo em Teixeira SD2. 
TEIXEIRA, J. (2019) "Significado e cores de nove provérbios portugueses sem cor" in Marques, Maria Aldina e Sánchez Rei, Xosé Manuel (eds.) Estudos atuais de linguística galego-portuguesa, Edicións Laiovento, Santiago de Compostela. [on-line] http://hdl.handle.net/1822/61026.

TEIXEIRA, J. (S/D), "Categorização e concetualização: da metáfora/metonímia e sinestesia à 'sintonímia"” (em fase de publicação). 